\title{
Editorial
}

\section{The epidemic of obesity publications, award to legend and more}

\section{Special issue on overweight and obesity}

The number of papers in the area of overweight and obesity submitted to our journal has increased immensely over the last few years. For this reason, we have chosen to devote this January 2011 issue solely to papers on this topic. The enclosed papers cover several areas such as monitoring and assessment ${ }^{(1-9)}$, determinants ${ }^{(10-18)}$, intervention ${ }^{(19)}$ and policy ${ }^{(20)}$, and originate from studies undertaken all over the world. We could point to the lack of intervention and policy papers as well as capacity building papers; they are still rare pieces for our journal and we certainly would like to see more of them.

We hope that this collection of papers will be of use for many of our readers. It provides a quick overview of ongoing research in the area of obesity, reflecting the important part of public health nutrition that it constitutes.

\section{Carlos Monteiro receives award and writes about ultra-processed food}

Another brilliant way of celebrating the new year with Public Health Nutrition is to highlight that our highly esteemed Associate Editor Professor Carlos Monteiro, from the University of Sao Paulo, Brazil, recently received an award from the Pan American Health and Education Foundation and the Pan American Health Organization. Carlos, you have our deepest appreciation: congratulations on the award and thank you for all the work you are doing for the journal!

In this issue we are also including a paper on ultraprocessed food ${ }^{(21)} \mathrm{co}-\mathrm{written}$ by Carlos. It is included in a series of papers, one of which was published in November 2010 in World Nutrition (www.wphna.org), and makes very interesting reading.

\section{Adding authors to an already published paper}

We have previously written about authorship and the problems related to this delicate issue in academic publishing. Over the years we have seen eminence authorships, gift authorships, ghost authorships and many more apart from those who are true authors according to the Vancouver rules. Information on authorship ethics can be found on the website of the Committee for Publication Ethics (http://publicationethics.org/) - where, among other important subjects, hands-on guidance regarding authorship disputes can be found by following the 'Guidelines' link.

We received a letter some time ago about a paper published previously in Public Health Nutrition with a request to add authors to this paper. The editorial board has been discussing how to deal with this issue, and we have now decided that we can let this pass as an corrigendum. You can find the corrigendum at the end of this issue. This corrigendum touches upon the issue of ghost authorships, where you have authors who have helped with the paper but are not included as authors. In this case, it seems to have been an oversight from those who submitted the paper. In other cases, data are handed over to someone who 'writes them up'. The latter problem is extremely difficult to deal with, both for those who lost 'their data' perhaps due to a supervisor's decision and for those who actually write and publish on data that rightfully should have been published by someone else. Authorship is one of the most difficult issues in academia, and should be handled properly.

The board of editors wish you an interesting, fruitful and successful publishing year in 2011!

\section{Agneta Yngve Editor-in-Chief \\ Marilyn Tseng Irja Haapala Allison Hodge Geraldine McNeill \\ Deputy Editors}

\section{References}

1. Pedrosa C, Correia F, Seabra D et al. (2011) Prevalence of overweight and obesity among 7-9-year-old children in Aveiro, Portugal: comparison between IOTF and CDC references. Public Health Nutr 14, 14-19.

2. Xiong F, Garnett SP, Cowell CT et al. (2011) Waist circumference and waist-to-height ratio in Han Chinese children living in Chongqing, south-west China. Public Health Nutr 14, 20-26.

3. Howel D (2011) Trends in the prevalence of obesity and overweight in English adults by age and birth cohort, 1991-2006. Public Health Nutr 14, 27-33.

4. Banks E, Jorm L, Rogers K et al. (2011) Screen-time, obesity, ageing and disability: findings from 91266 participants in the 45 and Up Study cohort. Public Health Nutr 14, 34-43. 
5. Stroebele N, Hill JO \& Willich SN (2011) Identifying the energy gap in the German population using results from representative national health surveys (1985-2002). Public Health Nutr 14, 44-48.

6. Starc G \& Strel J (2011) Tracking excess weight and obesity from childhood to young adulthood: a 12-year prospective cohort study in Slovenia. Public Health Nutr 14, 49-55.

7. Edwards KL, Clarke GP, Ransley JK et al. (2011) Serial cross-sectional analysis of prevalence of overweight and obese children between 1998 and 2003 in Leeds, UK, using routinely measured data. Public Health Nutr 14, 56-61.

8. Jackson RT, Al Hamad N, Prakash P et al. (2011) Waist circumference percentiles for Kuwaiti children and adolescents. Public Health Nutr 14, 70-76.

9. Beydoun MA, Fanelli Kuczmarski MT, Wang Y et al. (2011) Receiver-operating characteristics of adiposity for metabolic syndrome: the Healthy Aging in Neighborhoods of Diversity across the Life Span (HANDLS) study. Public Health Nutr 14, 77-92.

10. Duncan SJ, Duncan EK \& Schofield G (2011) Associations between weight perceptions, weight control and body fatness in a multiethnic sample of adolescent girls. Public Health Nutr 14, 93-100.

11. Kapantais E, Chala E, Kaklamanou D et al. (2011) Breakfast skipping and its relation to BMI and health-compromising behaviours among Greek adolescents. Public Health Nutr 14, 101-108.

12. Grau K, Tetens I, Bjørnsbo KS et al. (2011) Overall glycaemic index and glycaemic load of habitual diet and risk of heart disease. Public Health Nutr 14, 109-118.

13. Abdullah A, Stoelwinder S, Shortreed S et al. (2011) The duration of obesity and the risk of type 2 diabetes. Public Health Nutr 14, 119-126.
14. Valente H, Teixeira V, Padrão P et al. (2011) Sugarsweetened beverage intake and overweight in children from a Mediterranean country. Public Health Nutr 14, $127-132$

15. Kjøllesdal MR, Holmboe-Ottesen G \& Wandel M (2011) Frequent use of staff canteens is associated with unhealthy dietary habits and obesity in a Norwegian adult population. Public Health Nutr 14, 133-141.

16. Liberona Y, Castillo O, Engler V et al. (2011) Nutritional profile of schoolchildren from different socio-economic levels in Santiago, Chile. Public Health Nutr 14, 142-149.

17. Olinto MT, Willett W, Gigante DP et al. (2011) Sociodemographic and lifestyle characteristics in relation to dietary patterns among young Brazilian adults. Public Health Nutr 14, 150-159.

18. El Rhazi K, Nejjari C, Zidouh A et al. (2011) Prevalence of obesity and associated sociodemographic and lifestyle factors in Morocco. Public Health Nutr 14, 160-167.

19. Collins CE, Morgan PJ, Warren JM et al. (2011) Men participating in a weight-loss intervention are able to implement key dietary messages, but not those relating to vegetables or alcohol: the Self-Help, Exercise and Diet using Internet Technology (SHED-IT) study. Public Health Nutr 14, 168-175.

20. Thow AM, Heywood P, Leeder S et al. (2011) The global context for public health nutrition taxation. Public Health Nutr 14, 176-186.

21. Monteiro CA, Bertazzi Levy R, Moreira Claro R et al. (2011) Increasing consumption of ultra-processed foods and likely impact on human health: evidence from Brazil. Public Health Nutr 14, 5-13. 